\title{
Correction to: Special issue "Risk Considerations and Insurance in Developing Countries" of the Geneva Risk and Insurance Review
}

\author{
Mark Browne ${ }^{1}$ - Alejandro Del Valle Suarez ${ }^{2} \cdot$ Emmanuel Jimenez $^{3}$. \\ Calum G. Turvey ${ }^{4}$
}

Published online: 25 February 2022

(c) International Association for the Study of Insurance Economics 2022

\section{Correction to: The Geneva Risk and Insurance Review https://doi.org/10.1057/s10713-021-00073-4}

(1) Except for Alejandro del Valle, the authors Mark Browne, Emmanuel Jimenez, Calum $\mathrm{G}$ Turvey were not tagged correctly as authors of this editorial.

(2) The following footnote was not visible in the originally published editorial: The special issue includes papers that were presented at a conference held at St. John's University's Greenberg School. We recognize Travelers Foundation for support of the conference.

The original article has been corrected. We apologise for any inconvenience caused to our readers.

The original article can be found online at https://doi.org/10.1057/s10713-021-00073-4.

Alejandro Del Valle Suarez

adelvalle@gsu.edu

1 Maurice R. Greenberg School of Risk Management, Tobin College of Business, St. John's

University, Queens, NY 11439, USA

2 Department of Risk Management and Insurance, Georgia State University, 35 Broad Street NW, Atlanta, GA 30303, USA

3 Asian Development Bank, Manila, Philippines

4 Dyson School of Applied Economics and Management, S.C. Johnson Graduate School of Management, Cornell University, Ithaca 14853-6201, USA 